\title{
Epidemiology of cervical cancer development- a hospital based study
}

\author{
Das $C R^{1}$, Bose $\mathrm{S}^{2}$, Deka $\mathrm{M}^{3}$, Tiwari $\mathrm{D}^{4}$, Bose $\mathrm{PD}^{5}$, Das $\mathrm{GC}^{6}$ \\ ${ }^{1}$ Dr Chandana Ray Das MD, Assistant Professor, Department of Obstetrics \& Gynaecology, Gauhati Medical College, \\ Guwahati, Assam. ${ }^{2}$ Dr Sujoy Bose, Ph.D. Department of Biotechnology, ${ }^{3}$ Prof. Manab Deka, Ph.D. Department of \\ Biological Science, ${ }^{4}$ Diptika Tiwari, MSc. Department of Biotechnology. Gauhati University, Guwahati, Assam. ${ }^{5}$ Dr \\ Purabi Deka Bose, Ph.D. Department of Biotechnology, Pandu College, Assam, ${ }^{6}$ Prof. Gokul Ch Das, MD, Professor, \\ Department of Obstetrics \& Gynaecology, Gauhati Medical College, Guwahati, Assam.
}

Address for Correspondence: Dr Chandana Ray Das, E-mail: chandanaraydas@ yahoo.in

\begin{abstract}
Introduction: The present study is an attempt to detect Human papilloma virus infection and immunomodulation status in the development of carcinoma cervix. Methods: Cervical cancer cases were enrolled in between Jan' 2010 to Dec' 2012. Cervical tissue biopsies from the both the cancerous region as well as the non cancerous control area of the cervix, and whole blood $(3 \mathrm{ml})$ were collected from all the study subjects. The tissue samples were collected either in PBS or RNA later solution in vials and stored in $-80^{\circ} \mathrm{C}$ or liquid nitrogen till further use. Whole blood (2ml) was also collected from age matched voluntary female community controls $(n=50)$, the plasma was separated, and stored at $-20^{\circ} \mathrm{C}$ for cytokine analysis. Extracted DNA was then checked for presence of HPV DNA by PCR amplification method using MY09/11 primer. Th1 (IL-12) and Th2 (IL-10) were analysed both at protein as well as cervical tissue level. Results: The study showed $83.33 \%$ cases found to be HPV positive in cancerous area as well as in non cancerous area. There were other significant risk factor association of cervical cancer with early marriage in $70.36 \%$ and high parity $87 \%$ of cases. There is alteration of Th1 and Th2 ratio indicating immunomodulation plays an important role in the development of cervical cancer. Conclusion: The human papilloma virus infections are the major contributing factor as well as immunomodulation plays a major role in the development of cervical cancer in our region.
\end{abstract}

Keywords: Cervical Cancer, High Risk, Human Papilloma Virus, Polymerase Chain Reaction, Immunomodulation

\section{Introduction}

Cervical cancer remains a major cause of illness and all cancer-related deaths among women in developing countries [1]. It is one of the major significant cancers of all female neoplasms in developing countries, while in western countries it ranks as the tenth most common malignant disease [2]. Cervical cancer is the second most common cancer in women worldwide [3]. Every year 529,000 new cases detected and 275,000 deaths occur yearly. India accounts for more than $25 \%$ of the global cervical cancer burden. In India, the age standardized cervical cancer incidence and mortality rates were 27 and 15 per 100,000 women [4]. Cervical cancer is considered as a complex multi-step, multifactor process, and carcinogenesis occur as a result of multiple gene-environmental interactions [5]. A number

Manuscript received: $11^{\text {th }}$ Aug 2015

Reviewed: $17^{\text {th }}$ Aug 2015

Author Corrected: $27^{\text {th }}$ Aug 2015

Accepted for Publication: $5^{\text {th }}$ Sept 2015 of epidemiologic and molecular biologic data revealed that high-risk human papillomavirus (HPV) infection is the most well established environmental risk factor which is confirmed in $95 \%$ - $100 \%$ cases for cervical cancer [6]. The other risk factors known to increase the incidence of cervical cancer are early sexual practice, early marriage, teenage delivery of the first baby, multiparty, multiple sexual partners, poor practice of personal hygiene, low socio economic status, herpes simplex virus type II, HIV positivity, use of oral contraceptive pill, tobacco smoking etc $[7,8]$.

\section{Objectives}

1) To find out Human papilloma virus infection in cervical cancer development in the population of Assam

2) To analyze the immune-modulation status with respect to HPV related cervical malignancies. 


\section{Materials and Methods}

Cervical cancer patients $(n=102)$ who were diagnosed and clinically correlated by the registered clinician in the OPD of Obstetrics and Gynaecology, Guwahati Medical College hospital, were enrolled in the study with patient's informed consent and all clinical details. Tissue biopsies from the cancerous region as well as the non cancerous control area of the cervix, and whole blood $(3 \mathrm{ml})$ were collected from all the study subjects. A portion of the collected tissue samples were formalin fixed, paraffin embedded and was used for routine histopathological examination. Whole blood $(2 \mathrm{ml})$ was also collected from age matched voluntary female community controls $(n=50)$, the plasma was separated, and stored at $-20^{\circ} \mathrm{C}$ for cytokine analysis. Patients with history of previous treatment for cervical pre-cancerous lesions or cancer, and without informed consent were excluded from the study.

\section{Method}

HPV detection is done by using $\mathrm{L1}$ consensus primer MY09/11

My09: 5'CGTCCMARRGGAWACTGATC3'

My11: 5'GCMCAGGGWCATAAYAATGG3'

$\mathrm{M}=\mathrm{A}$ or $\mathrm{C}, \mathrm{W}=\mathrm{A}$ or $\mathrm{T}, \mathrm{Y}=\mathrm{C}$ or $\mathrm{T}, \mathrm{R}=\mathrm{A}$ or $\mathrm{G}$

\section{Reagents used for PCR amplification using MY09/11 primer} For $10 \mu \mathrm{l}$ of PCR reaction mixture

\begin{tabular}{|l|l|l|}
\hline S. No. & Chemicals used & Amount used \\
\hline 1 & Nuclease free water & $6.3 \mu \mathrm{l}$ \\
\hline 2 & $(10 \mathrm{x}) \mathrm{PCR}$ buffer & $1.0 \mu \mathrm{l}$ \\
\hline 3 & $(25 \mathrm{mM}) \mathrm{MgCl} 2$ & $1.0 \mu \mathrm{l}$ \\
\hline 4 & $(10 \mathrm{mM}) \mathrm{dNTP}$ & $0.2 \mu \mathrm{l}$ \\
\hline 5 & $(10 \rho \mathrm{m} / \mu \mathrm{l})$ primer forward & $0.2 \mu \mathrm{l}$ \\
\hline 6 & $(10 \rho \mathrm{m} / \mu \mathrm{l})$ primer backward & $0.2 \mu \mathrm{l}$ \\
\hline 7 & $(3 \mathrm{unit} / \mu \mathrm{l})$ Taq polymerase & $0.1 \mu \mathrm{l}$ \\
\hline 8 & Template & $1 \mu \mathrm{l}$ \\
\hline
\end{tabular}

Table 1: PCR master mix composition for my09/11 primer $(10 \mu \mathrm{l})$ : The amplification was carried out under the following reaction conditions for 35 cycles. Initial denaturation at $94^{\circ} \mathrm{C}--5 \mathrm{mins} /$ denaturation $94^{\circ} \mathrm{C}-30 \mathrm{secs} / \mathrm{annealing}$ $55^{\circ} \mathrm{C}-30 \mathrm{secs} /$ extension $72^{\circ} \mathrm{C}--45 \mathrm{secs} /$ final extension $72^{\circ} \mathrm{C}-7 \mathrm{mins} /$ hold at $4^{\circ} \mathrm{C}$ for $\infty$ (infinite), $5 \mu \mathrm{L}$ of the PCR product was analyzed on $1.5 \%$ of agarose gel.

Serum TH1/TH2 expression profile: The serum samples of both the cervical cancer patients and the controls were analyzed for Th1 (IL-12) and Th2 (IL-10) expression by Magpix multiplex ELISA method using customized magnetic bead based kit and Xpotent software based analysis (Millipore). As HPV was found to be significantly associated with the pathogenesis of cervical cancer, the cases showing positivity for presence of HPV were only included for the analysis.

Differential mRNA expression of Th1 (IL-12) and Th2 (IL-10) level: Total RNA extraction from affected and nonaffected comparative areas was done by standard trizol method. Expression of the mRNA transcriptions of IL-10, IL-12
Ethical review of the proposal and the consent: The research proposal was approved by the ethical review board of the Gauhati University. Informed consent was obtained from all participants prior to the sample collection.

HPV screening by PCR: Total DNA was isolated from both affected and non-affected areas by standard phenol-chloroform method. HPV detection was done in the DNA extracted from the cervical cancer tissue samples. As the viral DNA is found to be integrated in the host genome, whole genome extraction from the tissue was done. Presence of HPV was detected by PCR primer of HPV. The presence of HPV was confirmed by a bright band of $450 \mathrm{bp}$ size, after running the PCR product on agarose gel electrophoresis. amplification of the DNA by MY09/11 consensus 
isolated from the cervical cancer tissue samples was determined by the Real Time PCR which allows continuous measurement of the PCR product amount by means of SYBR Green fluorescent dye. The mRNA levels of the target genes are normalized to the transcript level of the housekeeping gene $\beta$-actin. For relative quantification analysis, the expression of mRNA transcripts of the target genes from normal cervical cancer tissues was also determined.

i) mRNA analysis of the IL-10 transcript: IL-10 expression was studied using the mRNA specific primers-

F: 5' TCT TGC AAA ACC AAA CCA Ca 3'

R: 5' ACT CTG CTG AAG GCA TCT CG 3'

ii) mRNA analysis of the IL-12 transcript: IL-12 expression was studied using the mRNA specific primers:-

F: 5' AAG GAG GCG AGG TTC TAA GC 3'

R: 5' GCA GGT GAA ACG TCC AGA AT 3'

iii) mRNA analysis of $\boldsymbol{\beta}$-actin as internal control: primer sequence is

F: 5' AGATAGTGGATCAGCAAGCAG 3'

R: 5' GCGAAGTTAGGTTTTGTCA 3'

$\beta$-actin was used as the internal control. The Real Time PCR conditions for $\beta$-actin were- $95^{\circ} \mathrm{C}-5$ mins $/ 95^{\circ} \mathrm{c}-30$ $\operatorname{secs} / 58^{\circ} \mathrm{C}-30 \operatorname{secs} / 72^{\circ} \mathrm{C}-45 \operatorname{secs}$.

Melt curve conditions: $95^{\circ} \mathrm{C}-15$ mins $/ 60^{\circ} \mathrm{C}-1 \mathrm{mins} / 95^{\circ} \mathrm{C}-15$ secs.

The statistical Analysis: Data were expressed as means \pm standard deviations (SD). Statistical analyses were performed using a Wilcoxon signed rank test for categorical variables and Mann-Whitney's non-parametric test appropriate. Differences were considered significant if $\mathrm{P}$ value is less than 0.05. The SPSS, version 13.0 software was used for statistical analysis.

\section{Results}

Demographical profile : The complete demographical characteristics of the patients were tabulated at the time of enrolment of the patients. The patients' age was grouped within range distribution of 10 years. The age ranges was from $30 \mathrm{yrs}$ to $70 \mathrm{yrs}$ of age. The mean age of patients was 43.68 years, and the highest number of cases belonged to patients aged $41-50$ years $(n=53 / 102,51.96 \%)$ followed by $31-40$ years age group $(n=36 / 102,35.29 \%)$ which signifies that HPV infection happens in the early and early-middle phases of life. This also indicates that the chances of carcinoma cervix are higher in perimenopausal age then at postmenopausal age.

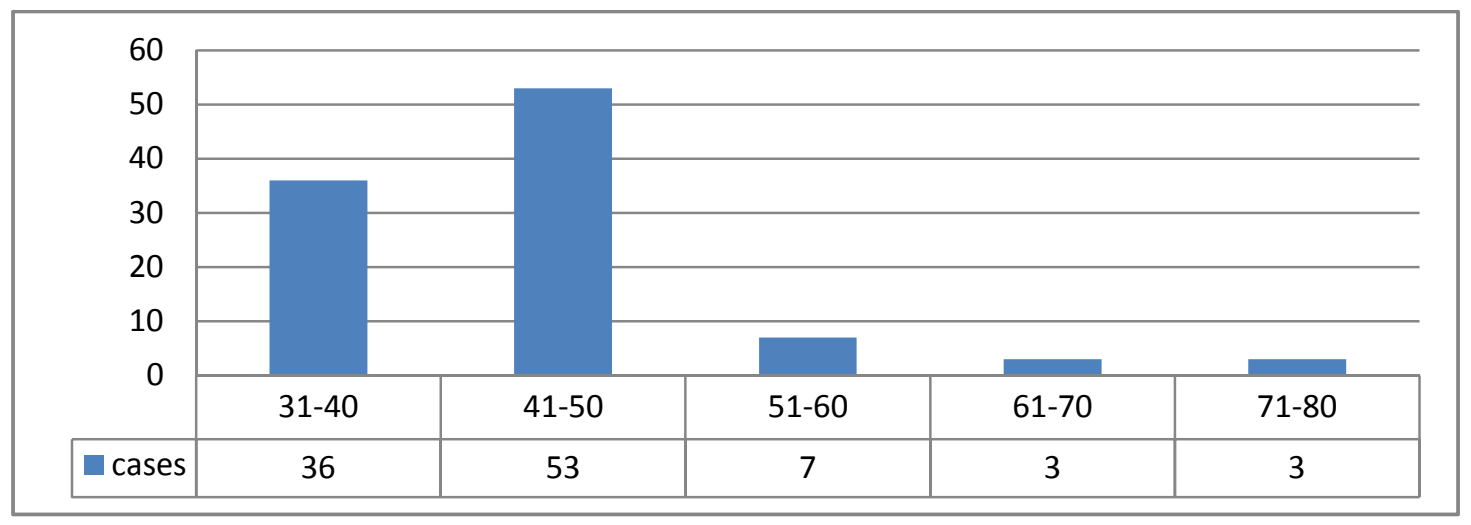

Fig 1: Showing age distribution of patients

\section{Social factor:}

A: Religion and Literacy: It was found that the occurrences of carcinoma cervix are more in Hindu population and significantly lower incidence in Muslim population. It was also found that the incidence is more in patients who are illiterate or received little educational training. 

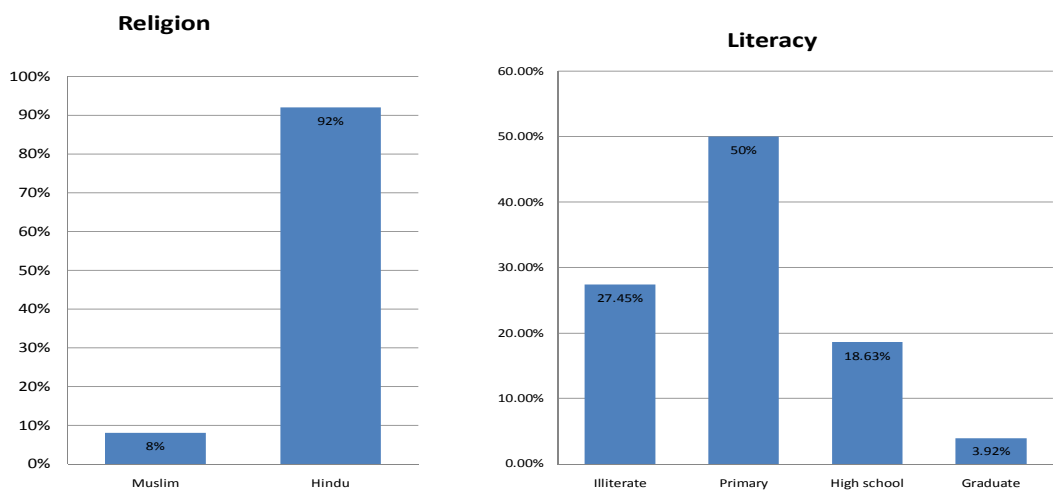

Fig 2: Showing literacy and religion status

B: Socioeconomic status and locality: In our study $79.41 \%$ patients is from lower socioeconomic status. It has been shown that women who belong to the lower social classes are more likely to contact and sustain cervical cancer. Patients in the lower socioeconomic status had significantly higher rates of late stage cancer diagnosis and lower rates of cancer survival.

Maximum number of patients was from rural background. Women in the rural area were less likely to be screened and often proper screening procedure is not available.

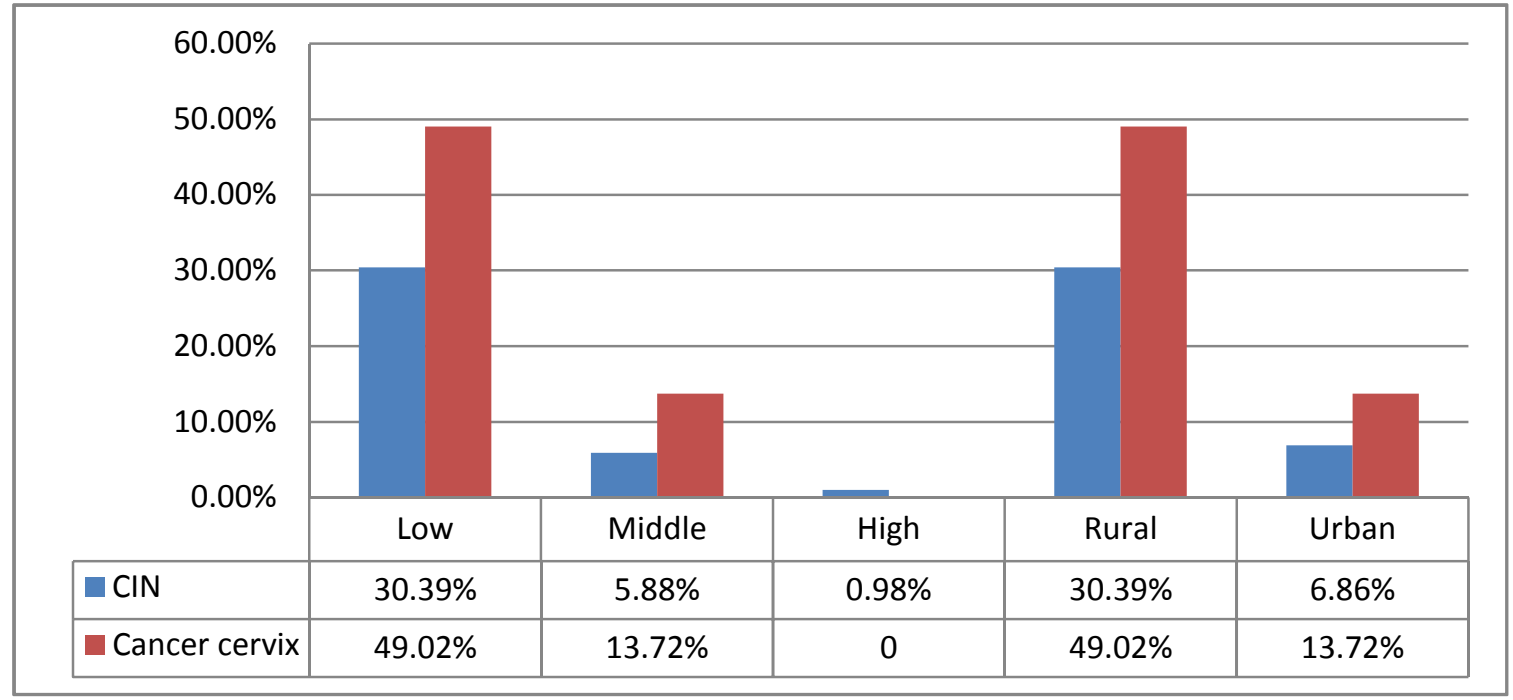

Fig 3: Relation of socioeconomic status and locality to cervical cancer

\section{Clinical risk factors:}

A: Age of marriage and age of first pregnancy: $70.57 \%$ patients got pregnant before the age of 20 years and only $29.4 \%$ patients got their first child above the age of 20 years. The risk of cervical cancer increases with the first onset of sexual activity. In addition, the incidence of cervical cancer declines as the age of marriage increases. 


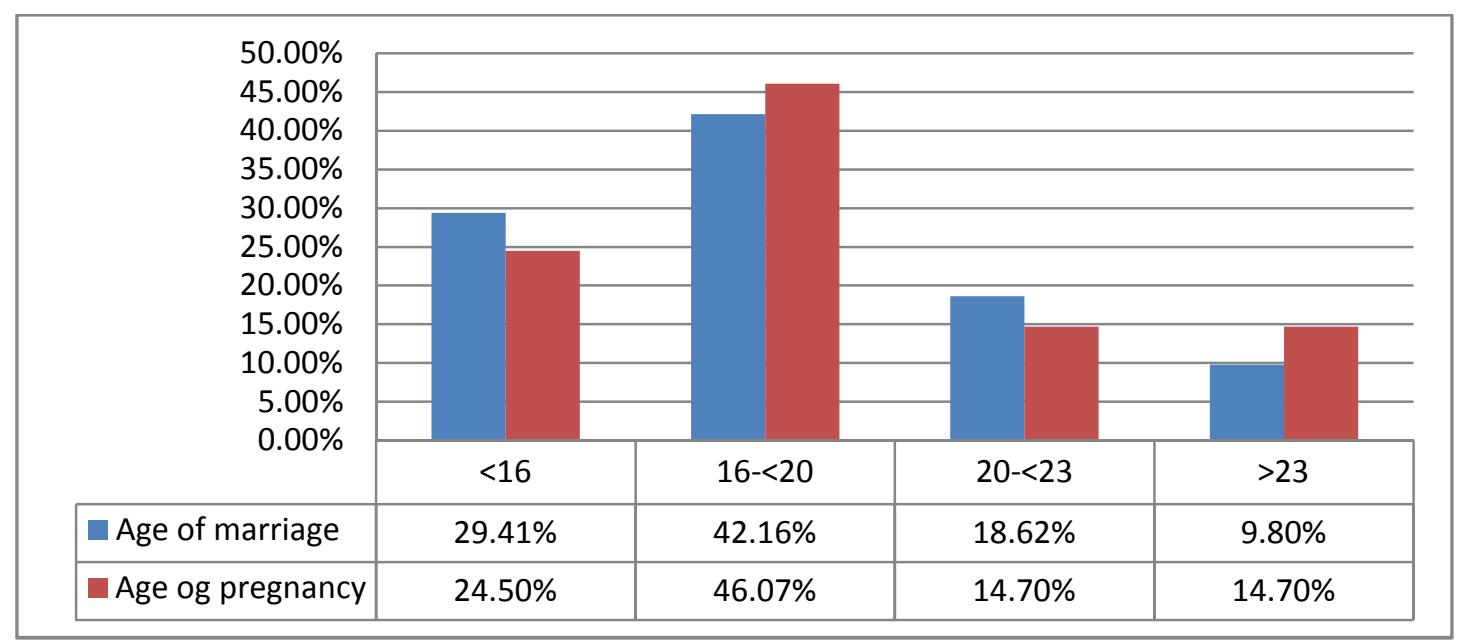

Fig 4: Relation of age of marriage and first pregnancy to cervical cancer

B: Relation with parity: It has been seen that cervical cancer development is high as parity is more. $57.84 \%$ cases were parity 4 . The risk increases with multiple child birth. In the present study had $96.05 \%$ of females had with multiple childbirth.

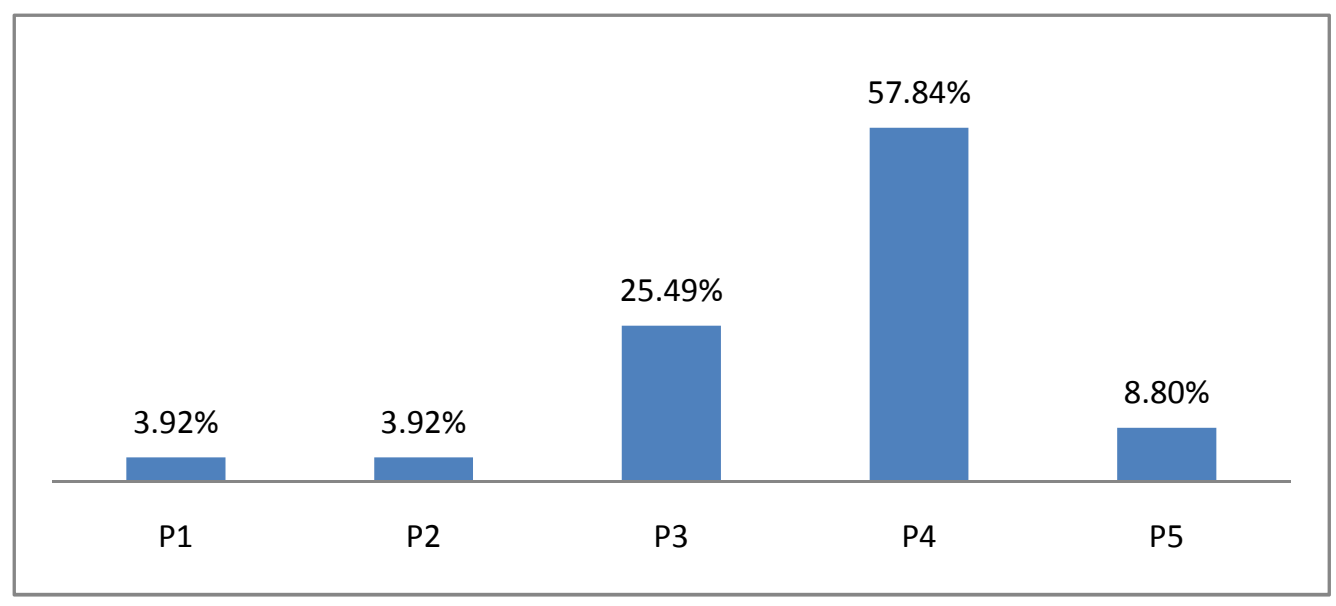

Fig 5: Relation of parity to cervical cancer

HPV screening analysis:

HPV prevalence:

Overall, out of the 102 cases screened, HPV infection was observed in $85(83.33 \%)$ patients in both affected and nonneoplastic control areas. Wilcoxon signed rank test based analysis shows that HPV infection was significantly associated with cervical cancer development $(\mathrm{p}<0.001)$.

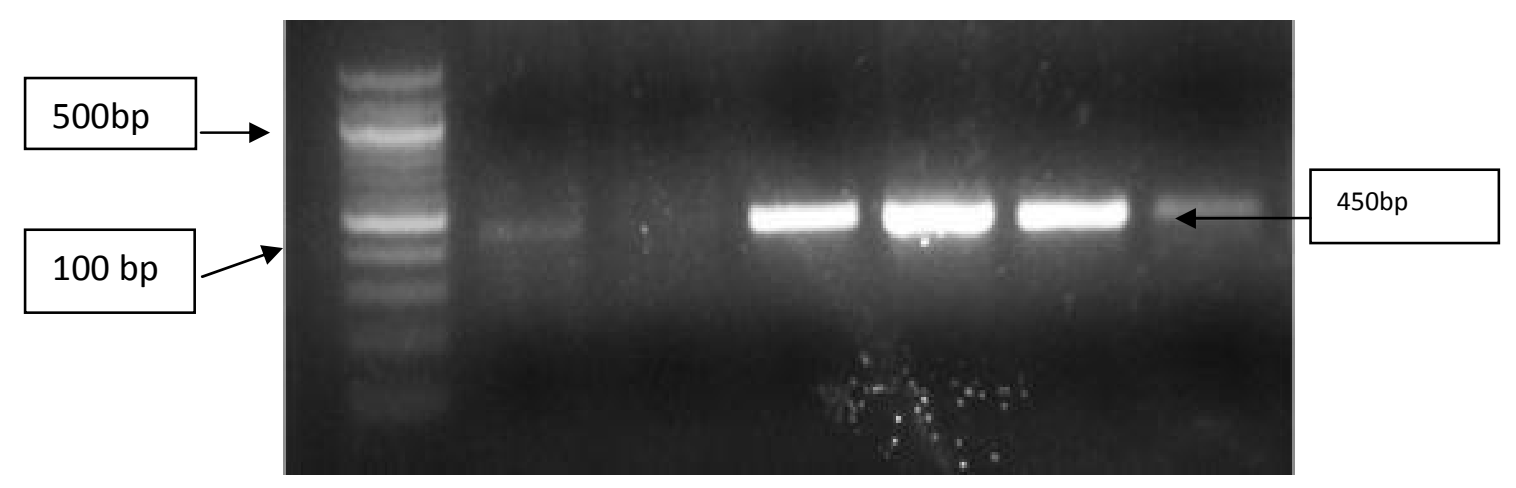


Fig 6: Representative photograph of agarose Gel electrophoresis picture of PCR amplification of HPV (product size 450bp)

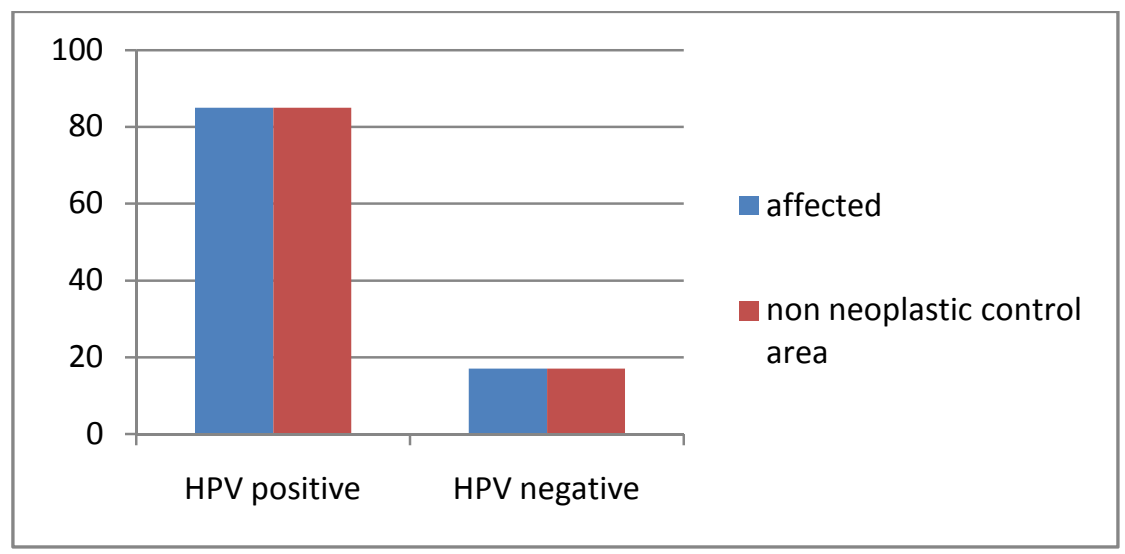

Fig 7: Relation of age and detection of HPV infection to the occurrence of carcinoma cervix:

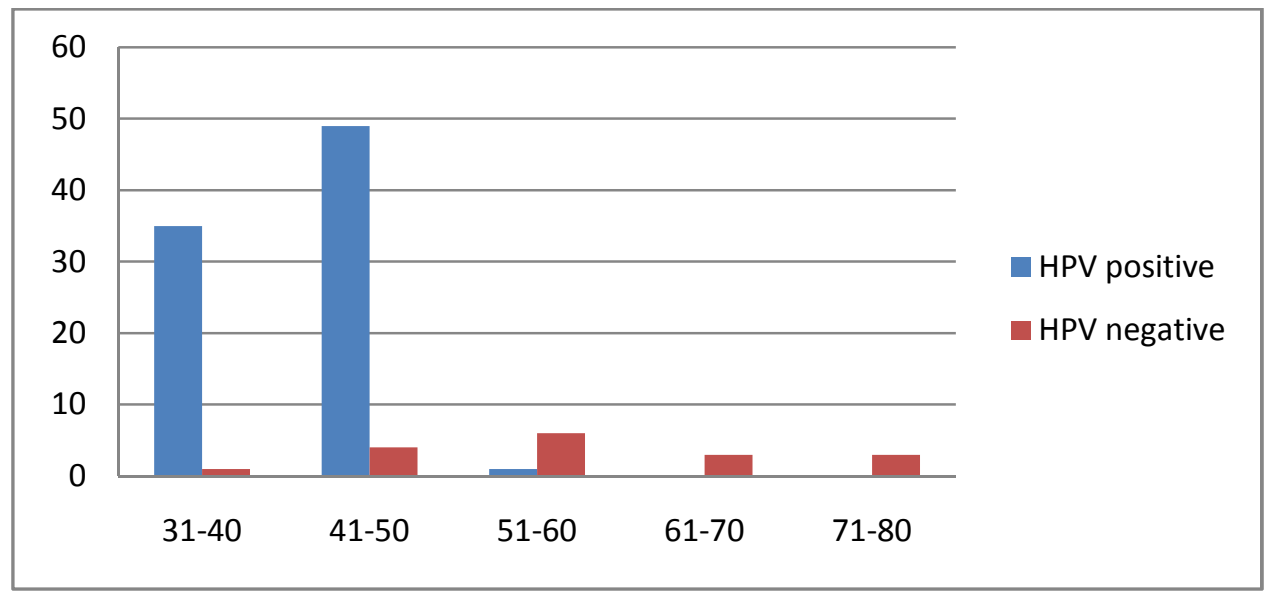

Fig 8: Relation of age and detection of HPV infection to the occurrence of carcinoma cervix

In India average menopausal age is fifty (50) years. In the present study, majority of cervical cancer cases $89(87.25 \%)$ were below 50 years of age, which was found to be statistically significant by virtue of Wilcoxan signed rank test based analysis $(\mathrm{p} \leq 0.001)$.

Mann-Whitney statistical analysis based results shows that HPV infection was significantly associated with the development of cervical cancer in the early reproductive phase $\leq 50$ years of life $(\mathrm{P} \leq 0.001)$ thus; indicating premenopausal patients are mostly suffering.

Differential Th1/Th2 modulation in the development \& progression of cervical cancer at serum level: The differential expression of Th1/Th2 modulation of the collected samples in control versus HPV positive cervical cancer patients was studied by the Magpix multiplex ELISA method using customized magnetic bead based kit and Xpotent software based analysis (Merck Millipore). From the data obtained, it was seen that expression of Th1 and Th2 are lower in the affected areas than the control ones and thus the Th1:Th2 ratio also decreases in the affected areas. Thus, it can be inferred that the modulation of Th1 and Th2 expression plays a major role in predisposing the patient to the development of cervical cancer.

IL-12 / IL-10: 
In affected patients IL-10 response is more than the control one thus it shows inhibition of immune responses. The ratio of IL-12/IL-10 decreases in cancer, suggestive of the fact that Th1 type response is a prerequisite in limiting the progression to cervical cancer from normal.

\begin{tabular}{|l|l|l|l|}
\hline CASES & IL-12 $($ Th1 $)(\mathbf{p g} / \mathbf{m l})$ & IL-10 $(\mathbf{T h} 2)(\mathbf{p g} / \mathbf{m l})$ & IL-12 / IL-10 $($ Th1/Th2) \\
\hline Control & 1.718711 & 0.091162 & 18.853370 \\
\hline Affected & 1.295103 & 0.275243 & 4.705307 \\
\hline
\end{tabular}

Table 1: Showing the modulation of IL-12 \& IL-10 in affected and control

Differential Th1/Th2 modulation in the development \& progression of cervical cancer at transcript level:

A. Differential IL-10 expression at mRNA level in cervical tissue: Differential fold change in IL-10 mRNA expression between HPV infected affected and paired non-neoplastic control areas of cervix was studied by real time PCR using $\beta$-actin for internal normalization control. The mRNA based expression analysis showed up regulation in IL10 expression (1.608 \pm 0.944$)$ in affected area compared to non-neoplastic control areas in the HPV positive cases.

B: Differential IL-12 expression at mRNA level in cervical tissues: Study of the mRNA expression of IL-12 was done using IL-12 mRNA specific primer by Real Time PCR method using cDNA which was prepared from extracted RNA of the samples from both cancerous and paired non neoplastic control area. The expression of IL-12 was found to be comparative between control and affected area (1.015 \pm 0.623 folds).

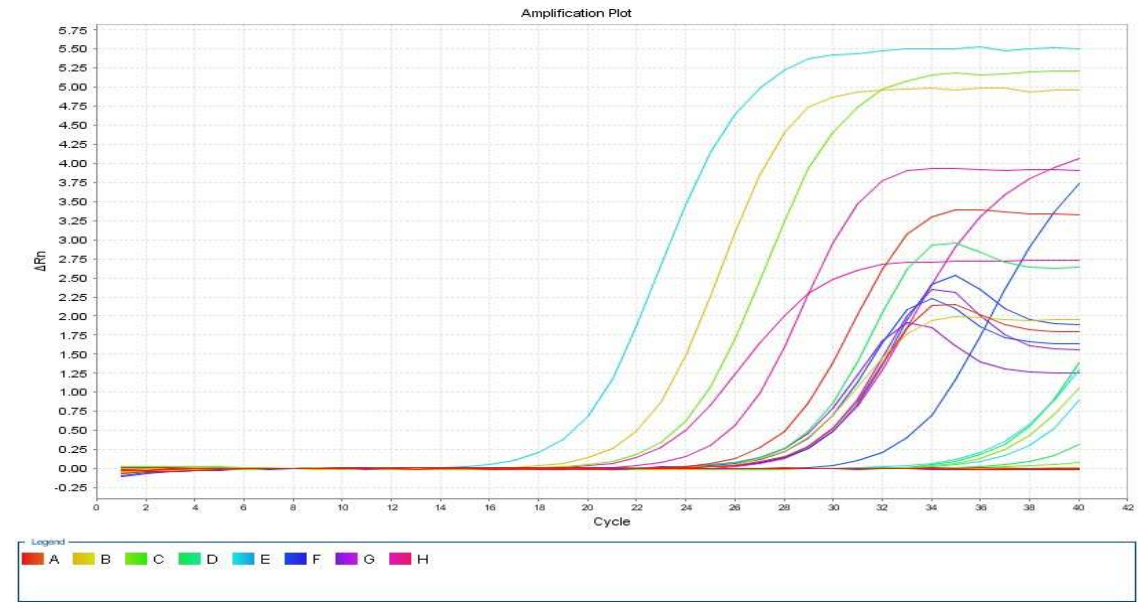

Fig 9: showing amplification plot

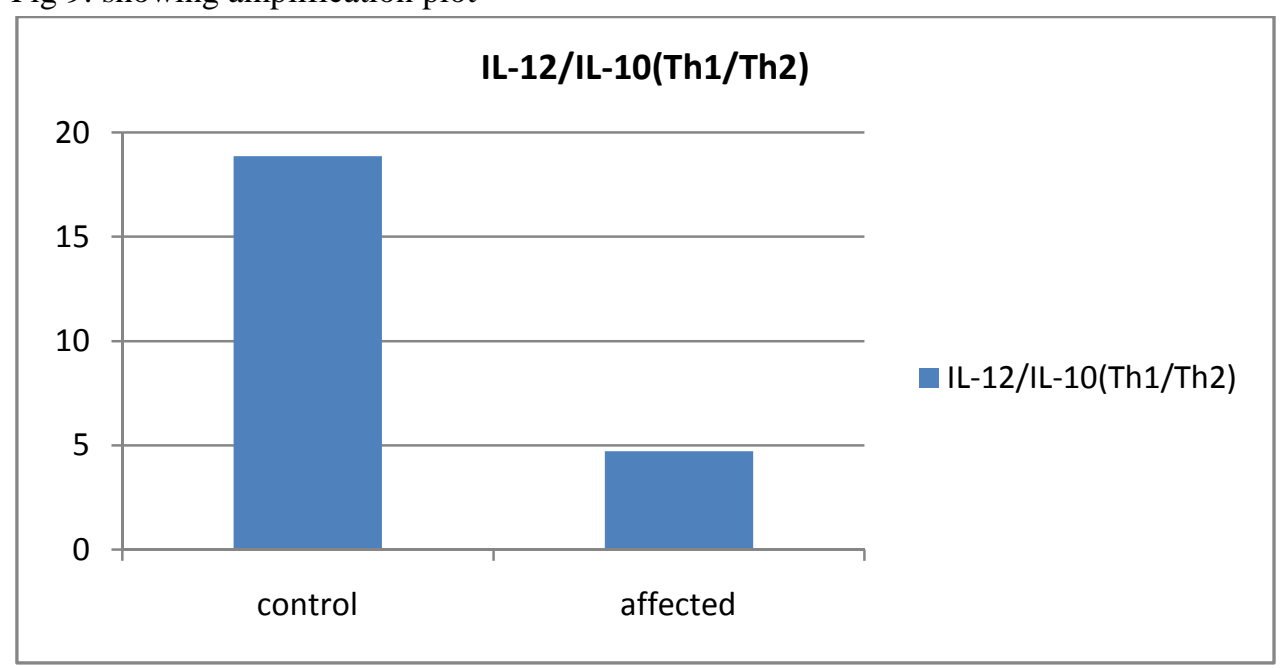

Fig 10: showing ratio between Th1 and Th2 


\section{Discussion}

Cervical cancer is one of the most common cancers among women and is the 2nd most cause of cancer death among women in India [9, 10]. The cases of cervical cancer remain high despite the availability of HPV vaccine and it has been seen that the cervical cancer cases are increasing being the second highest incidence rate in the world among women after breast cancer [3]. Infection of the cervix with human papilloma virus (HPV) has been established as a key determinant of cervical carcinogenesis [11].

One of the most important information from the present study was the apparent strong correlation between the ages at marriage with the chances of incidence of cancer cervix. About $70.36 \%$ women in our study got pregnant before the age of 20 years and only $28.16 \%$ of patients got their first child above the age of 20 years. Patients who had conceived before 20 years, incidence of carcinoma cervix were found to be high. In consistence with the correlation between chance of occurrence of carcinoma cervix and the age of marriage, similar relation was also observed with the age at first pregnancy by J.T. Boyd and co-workers who showed similar result with increased risk of developing carcinoma cervix in women who got pregnant before the age of 18 years [12]. In a case control study by Biswas $\mathrm{L} \mathrm{N}$ et al, showing maximum risk in women who reported their first intercourse at less than 12 years of age [13].

In our study, incidence of cervical cancer was less in Muslim population than Hindus. It may be due to circumcision statuses which lead to less HPV virus colonization in penis [14, 15, and 16].

Studies have shown that women who belong to the lower social classes are more likely to contact HPV infection and subsequently progress to cervical cancer. It has been seen that patients in the lower socioeconomic class had higher prevalence of cervical cancer. Incidence of cervical cancer also increased in illiterate or patients who received little to no educational training [17]. Furthermore, lower socio economic classes are less likely to be screened and at times health care facility is not reachable even if they did contact with HPV with presence of sign, symptoms [17]. Eventually, lower socioeconomic status is observed to be the confounding factor in higher cervical cancer rates in our study, similar finding was found in other study [18].

It was observed that during personal interviews many of the patients were unable to understand what can be defined as infection and failed to seek any medical opinion for their infection related symptoms. This lack of awareness may have root in the fact that $77 \%$ of the patients were educated up to primary level which was correlating with other study by D Das et al, [8]. It is well recognized that cervical cancer risk is associated with a low socio-economic status, as defined by education or income levels.

In the present study had $96.22 \%$ of females had with multiple childbirth. Study by E.L. Wynder and his co-workers showed that increased risk is directly proportional to parity [19].

The mean age of patients was 43.68 years and the most vulnerable age group of cervical cancer in the present study was 41-50 years followed by the age group 31-40 years which signifies that HPV infection happens in the early and early-middle phases of life. This indicates that the chances of carcinoma cervix are higher in perimenopausal age then at postmenopausal age. In our study, cervical cancer cases mostly found below 50 year of age and HPV infection significantly associated with the development of cervical cancer ( $p$ value is $<0.001$ ) which is similar with other studies like Munoz $\mathrm{N}$ et al, [20]. It is already documented that the majority of HPV infections are cleared spontaneously from cervical area by cell mediated immunity and lower rate of clearance of HPV16 infection in women less than 30 years of age was observed. Viral load is the main determinant of persistence, and persistence of HPV infections carries a higher risk of $\mathrm{CIN} 2 / 3$, which is inversely associated with clearance [20]. Spontaneous clearance of the HPV is one of the important contributing factors for negative result of HPV infection in non cancerous area in our study.

Available literature is suggestive that, other than HPV infection are host genetic and immunological factors the most specific factor(s) responsible for cervical cancer development [21]. Study shows that neoplastic diseases of human are usually associated with deregulations of the equilibrium 
between the production of certain type 1 and type 2 cytokines [22]. Analysis of T helper type 1 (Thl) and type 2 (Th2) cytokine profiles has been used to characterize the immune response in several human diseases, including HPV-associated diseases [23]. In our study, differential Th1 and Th2 modulation study in the serum level it was found that production of type 2 cytokines (IL-10) was comparatively higher with down-regulation of Th1 in cancer cervix cases than controls. With respect to the Th1/Th2 status, the ratio of IL-12/IL-10 decreases in cancer compared to non neoplastic control cases, suggestive of the fact that Th1 type response is a prerequisite in limiting the progression to cervical cancer. Thus, the differential modulation of Thl and Th2 expression plays a major role in predisposing the patient to the development of cervical cancer. There is increased level of type 1 cytokines in controls indicating that Th1 are immune stimulatory and are thus capable of limiting tumor progression. But in cancer cases, the production of $\mathrm{Th} 2$ (IL-10) is abnormally elevated as compared to production of IL-12 in HPV infected patients. Reports from other research group has stated that IL-12 is the potent activator of cellular immunity and has antitumor and anti metastatic against tumors [24, 25], thus decreasing production of IL-12 indicating suppression of immunity due to HPV infection in our study. IL-10 down regulates tumor specific immune response by directly suppressing IL-12 production thereby preventing the activation of CTLs and Natural Killer Cells which indicates a Th2 skewed status predisposing to HPV infection and resulting progression to cancer cervix in our case, similar to reports from other groups [26]. Similar finding was reported by Giannini et al, and Mota et al, where they have mentioned that peripheral blood mononuclear cells (PBMC) from patients with both squamous intraepithelial lesions (SIL) and cervical cancer produced decreased amount of IL-12 and IFN- $\gamma$ and increased level of IL-4 and IL-10 [27,28]. An increased number of IL-10-positive cells were detected in the cervix of patients with cervical intraepithelial neoplasia (CIN) [29]. It has also been demonstrated that basal levels of IL-10 are augmented in the peripheral blood mononuclear cell of patients with SIL [30]. Serum levels of IL10 were observed to be significantly higher in women with invasive cervical cancer and high grade CIN as compared to controls [5].
In differential mRNA expression profile of Th1 and Th2 makers the data clearly indicates an upregulation of IL-10 (Th2) and either downregulation or non-sufficient stimulation (IL-12) of Th1 response in the pathogenesis of cervical cancer. Similar to the Th1/Th2 profile at serum level; we found that differential expression at mRNA level, and was directly associated with the severity of the disease. Scientific evidence shows that during the process of cancer development in the epithelium of cervix there is shifting of cytokines from Thl to Th2 cytokines which supports our data. It has been demonstrated that IL-10 is highly expressed locally in biopsies from patients with premalignant lesions and cervical cancer and may encourage a confined state of immune suppression [31]. Earlier studies have also reported that the immune responses against tumor were mainly mediated by Thl cells. Imbalance of the Th $1 / \mathrm{Th} 2$ ratio with increase of Th2 cells, the immune response of the body against the tumor would be severely destabilized which will propagate to the cancerous growth of the tumor [32] which might be the underlying factor in our case cohorts. The expression of cytokine mRNA transcripts at the site of HPV infection in relation to development of cervical neoplasia found a reduced type 1 immunity correlating with HPVinduced invasive cervical carcinoma [33]. HPVinduced immunity is crucial for clearance of the infection [33].

As the affected areas of the study samples show lower expression of these host immunological factor than the non-affected areas, it may be suggested that under expression of key mediators of Th1 cytokine profile is detrimental for the pathogenesis of HPV infection mediated cervical cancer development.

\section{Conclusion}

To conclude, present study shows that apart from some demographical, clinical and sociological factors; infection with HPV is the most important factor associated with cervical cancer disease burden in our study cohort. Deregulation in the immunological profile of the host, resulting in suppression/inadequate activation of Th1 cytokine profile is a deciding factor in the progression of HPV mediated cervical anomalies to cancer. 
Acknowledgement: The authors want to thanks all the subjects participating in the study.

\section{Funding: Nil}

Conflict of interest: None.

\section{References}

1. Jemal A, Siegel R, Xu J, Ward E. Cancer statistics, 2010. CA Cancer J Clin, 2010 Sept-Oct; 60(5): 277300.doi:10.332/caac.20073.Epub2010 Jul7.

2. Parkin DM, Ohshima H, Srivatanakul P, Vatanasapt V.Cholangiocarcinoma: epidemiology, mechanisms of carcinogenesis and prevention. Cancer Epidemiol Biomarkers Prev. 1993 2(6):537-44.

3. Ferlay J, Soerjomataram I, Dikshit R, Eser S, Mathers C, Rebelo M, Parkin DM, Forman D, Bray F.Cancer incidence and mortality worldwide: sources, methods and major patterns in GLOBOCAN 2012. Int $\mathbf{J}$ Cancer. 2015; 136(5):E359-86.

4. Ferlay J, Shin HR, Bray F, Forman D, Mathers C,Parkin DM. Estimates of worldwide burden of cancer in 2008: GLOBOCAN 2008. Int J Cancer. 2010 Dec 15;127(12):2893-917. doi: 10.1002/ijc.25516.

5. Feng Pan, Jing Tian, Chu-Shu Ji, Yi-Fu He, XingHua Han ,Yong Wang ,Jian-Ping Du, Feng-Shou Jiang , Ying Zhang, Yue-Yin Pan, Bing Hu. Association of TNF- $\alpha-308$ and -238 Polymorphisms with Risk of Cervical Cancer: A Meta-analysis Asian Pacific J Cancer Prev,2012; 13 (11): 5777-5783

6. Zur Hausen H. Papillomaviruses and cancer: from basic studies to clinical application. Nat Rev Cancer. 2002 May;2(5):342-50.

7. Raychaudhuri S, Mandal S. Current status of knowledge, attitude and practice (KAP) and screening for cervical cancer in countries at different levels of development. Asian Pac J Cancer Prev. 2012;13(9):4221-7.

8. Debabrata Das, Avdhesh Kumar Rai, Amal Chandra Kataki, et al. Nested Multiplex PCR Based Detection of Human Papillomavirus in Cervical Carcinoma Patients of North- East India. Asian Pacific J Cancer Prev, 2013; 14 (2): 785-790.

9. Benjamin E. Greer; Wui-Jin Koh; Nadeem R. et al. Cervical cancer: Clinical practice guidelines in oncology. Journal of the National Comprehensive Cancer Network. JNCCN Journal of the National Comprehensive Cancer Network. 2010;8(12):13881416.

10. Chopra R. The Indian scene. J Clin Oncol. 2001 Sep 15;19(18 Suppl):106S-111S.

11. Castellsagué X. Natural history and epidemiology of HPV infection and cervical cancer. Gynecol Oncol. 2008 Sep;110(3 Suppl 2):S4-7. doi: 10.1016/j.ygyno.2008.07.045.

12. Boyd, J.T., Doll, R. A Study of the Aetiology of Carcinoma of Cervix Uteri. Br J Cancer.1964; 18(3):419-434.

13. Biswas LN, Manna B, Maiti PK, Sengupta S. Sexual risk factors for cervical cancer among rural Indian women: a case-control study. Int. J. Epidemiol 1997; 26 (3): 491-495. doi: 10.1093/ije/26.3.491.

14. Castellsagué X, Bosch FX, Muñoz N . The male role in cervical cancer. Salud Publica Mex. 2003; 45 (3):345-53.

15. Louie KS, de Sanjose S, Mayaud P. Epidemiology and prevention of human papillomavirus and cervical cancer in sub-Saharan Africa: a comprehensive review. Trop Med Int Health. 2009 Oct; 14(10):1287-302.

16. Paul Satya B, Tiwary Basant K, Choudhury Arun Paul. Studies on the Epidemiology of Cervical Cancer in Southern Assam. Assam University Journal of Science \& Technology .Biological and Environmental Sciences. 2011; 7(1):36-42.

17. Savita Malik. The Epidemiology of Cervical Cancer in Women in India. March, 2005. Epidemiology HED 825 .

18. Juneja A, Sehgal A, Mitra AB, Pandey A. A survey on risk factors associated with cervical cancer. Indian $\mathbf{J}$ Cancer. 2003 Jan-Mar;40(1):15-22.

19. Wynder, E.L., Cornfield, G., Schroff, P.D, Doraiswami, K.R. Study of environmental factors in carcinoma of the cervix. Am J Obstet Gynaeco, 1954; 68(4):1016-1047.

20. Munoz N, Hernandez-Suarez G, Méndez F et al. Persistence of HPV infection and risk of high-grade cervical intraepithelial neoplasia in a cohort of 
Colombian women. Br J Cancer. Apr 7, 2009; 100(7): 1184- 1190 .

21. Deng CX. SIRT1, Is it a tumor promoter or tumor suppressor? Int J Biol Sci, 2009 Jan21; 5(2): 147-52.

22. Bais AG, Beckmann I, Lindemans J, et al. A shift to a peripheral Th2-type cytokine pattern during the carcinogenesis of cervical cancer becomes manifest in CIN III lesions. Journal of Clinical Pathology. 2005; 58(10):1096-1100.

23. Clerici M, Merola M, Ferrario E, et al. Cytokine production patterns in cervical intraepithelial neoplasia: association with human papillomavirus infection. J Natl Cancer Inst. 1997; 89:245-50.

24. Clerici M, Shearer GM, Clerici E. Cytokine dysregulation in invasive cervical carcinoma and other human neoplasias: time to consider the TH1/TH2 paradigm. J Natl Cancer Inst. 1998 Feb 18;90(4):261-3.

25. Zhu X, Jin L, Zou S, Shen Q, Jiang W, Lin W, Zhu $\mathrm{X}$. Immunohistochemical expression of RAGE and its ligand (S100A9) in cervical lesions. Cell Biochem Biophys. 2013 Jul;66(3):843-50. doi: 10.1007/s12013013-9515-X..

26. Mosmann TR, Coffman RL. Two types of mouse helper T-cell clone Implications for immune regulation. Immunol Today. 1987;8(7-8):223-7. doi: 10.1016/01675699(87)90171-X.

\section{Giannini SL, Al-Saleh W, Piron H, Jacobs} N, Doyen J, Boniver J, Delvenne P. Cytokine expression in squamous intraepithelial lesions of the uterine cervix: implications for the generation of local immunosuppression. Clin Exp Immunol. 1998 Aug;113(2):183-9.

28. Mota F, Rayment N, Chong S, Singer A, Chain B. The antigen-presenting environment in normal and human papillomavirus (HPV)-related premalignant cervical epithelium. Clin Exp Immunol. 1999 Apr;116(1):33-40..

29. Mindiola R, Caulejas D, Núñez-Troconis J, Araujo M, Delgado M, Mosquera J. Increased number of IL-2, IL-2 receptor and IL-10 positive cells in premalignant lesions of the cervix. Invest Clin. 2008 Dec;49(4):53345 .

30. Jacobs N, Giannini SL, Doyen J, Baptista A, Moutschen M, Boniver J, Delvenne P. Inverse modulation of IL-10 and IL-12 in the blood of women with preneoplastic lesions of the uterine cervix. Clin Exp Immunol. 1998 Jan;111(1):219-24.

31. Vidal AC, Skaar D, Maguire R et al . IL-10, IL-15, IL-17, and GMCSF levels in cervical cancer tissue of Tanzanian women infected with HPV16/18 vs. nonHPV16/18 genotypes. Infect Agent Cancer. 2015 Mar 20;10:10. doi: 10.1186/s13027-015-0005-1. eCollection 2015.

32. Chen Z, Ding J, Pang N, Du R, Meng W, Zhu Y, Zhang Y, Ma C, Ding Y. The Th17/Treg balance and the expression of related cytokines in Uygur cervical cancer patients. Diagn Pathol. 2013 Apr 15;8:61. doi: 10.1186/1746-1596-8-61.

33. de Gruijl TD, Bontkes HJ, Walboomers JM, Coursaget P, Stukart MJ, Dupuy C, Kueter E, Verheijen RH, Helmerhorst TJ, Duggan-Keen MF, Stern PL, , Meijer CJ, Scheper RJ. Immune responses against human papillomavirus (HPV) type 16 virus-like particles in a cohort study of women with cervical intraepithelial neoplasia. I. Differential T-helper and $\mathrm{IgG}$ responses in relation to HPV infection and disease outcome. J Gen Virol. 1999 Feb; 80 (Pt 2):399-408.

\section{How to cite this article?}

Das CR, Bose S, Deka M, Tiwari D, Bose PD, Das GC. Epidemiology of cervical cancer development- a hospital based study. Int J Med Res Rev 2015;3(8):815-825. doi: 10.17511/ijmrr.2015.i8.153. 